\title{
Semblanza del único obispo angelopolitano de origen criollo en el periodo de los Austria: Alonso de la Mota y Escobar

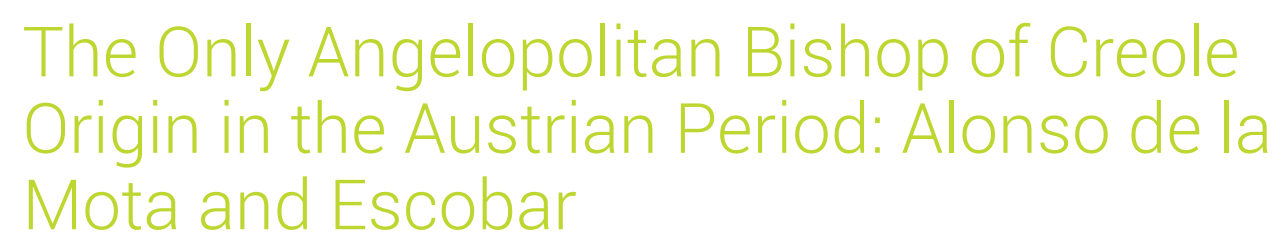

Juan Pablo Salazar Andreu

Universidad Popular Autónoma del Estado de Puebla MÉXICO

juanpablo.salazar@upaep.mx

[Hipogrifo, (issn: 2328-1308), 7.2, 2019, pp. 863-871]

Recibido: 23-05-2018 / Aceptado: 28-06-2018

DOl: http://dx.doi.org/10.13035/H.2019.07.02.59

Resumen. Don Alonso de la Mota y Escobar fue un hombre instruido y con gran experiencia política que ocupó la mitra angelopolitana, en ese momento todavía obispado de Tlaxcala, destacando por sus buenas relaciones con las autoridades virreinales y el desarrollo de obras de gran relevancia en la educación. El presente trabajo, basado en un análisis histórico, muestra el desarrollo de su labor en lo que sería la diócesis de Puebla.

Palabras clave. Virreinato; criollo; Obispado de Tlaxcala; Obispado de Puebla; Colegio de San Ildefonso.

Abstract. Don Alonso de la Mota y Escobar was an educated man with great political experience who occupied the angelopolitan miter, at that time still bishopric of Tlaxcala, standing out for his good relations with the viceroyal authorities and the development of works of great relevance in education. The present work, based on a historical analysis, shows the development of its work in what would be the diocese of Puebla.

Keywords. Viceroyalty; Criollo; Bishopric of Tlaxcala; Bishopric of Puebla; College of San Ildefonso. 


\section{BIOGRAFÍA DE DON ALONSO DE LA MOTA Y ESCOBAR}

Don Alonso de la Mota y Escobar fue el primer obispo poblano del siglo XVIII, además de ser el primer y único obispo de origen criollo del periodo de los Austria, con lo cual se rompió una tradición real de prelados peninsulares. Fue también, entre diciembre de 1590 y febrero de 1595, el primer miembro y deán del cabildo de Puebla que ha ocupado la sede episcopal angelopolitana'.

En su calidad eclesiástica, mantuvo relaciones armoniosas con los virreyes Luis de Velasco II, fray García Guerra, Diego Fernández de Córdoba, marqués de Guadalcázar, el marqués de Gelves y Rodrigo Pacheco y Osorio, marqués de Cerralvo.

Si bien su origen es novohispano, el lugar específico de su nacimiento es hasta ahora objeto de controversia entre historiadores, ubicando tanto a la Ciudad de Puebla de los Ángeles, como a la Ciudad de México o bien a la antigua Villa de Carrión, en el actual Atlixco, como el lugar donde primero vio la luz; esto, el 18 de marzo de 15462. Una fuerte línea teórica subraya la lógica de que el futuro prelado naciera en la ciudad de México, dado que don Gerónimo Ruiz de la Mota fue alcalde de dicha ciudad. Como señala Ramírez Cabañas,

Un cronista coetáneo del prelado indica que este nació en la ciudad de México y en tiempos del primer arzobispo, habiéndosele bautizado en la catedral y el canónigo don Vicente de P. Andrade publicó la fe del bautismo, que fija la fecha del nacimiento en el día 18 de mayo de 1546 y señala progenitores al capitán Gerónimo Ruiz de la Mota y «su mujer legítima Catalina Escobar»; el documento procede del archivo del Sagrario Metropolitano ${ }^{3}$.

Por parte de padre y madre le viene la hidalguía de antepasados conquistadores; sin embargo, respecto a sus padres existe todavía cierta controversia:

En uniformidad casi constante los cronistas y los historiadores cuyas obras consignan datos referentes a la persona y vida de Mota y Escobar, siguen en sus noticias al maestro Gil González Dávila, aceptando que fue hijo de Antonio de la Mota y de doña Francisca de Orduña y Luyando, con la peregrina circunstancia de que no identificaron siquiera a este don Antonio, pues Mota Padilla escribía ya en el siglo XVIII: «No sé si don Antonio era hijo de Francisco de la Mota, el que murió en el Mixton, o de Gerónimo Ruiz de la Mota, que sirvió también a su Majestad en la conquista de la Nueva España»; y es extraña la duda en tal autor, si aceptamos todas las conclusiones de García Icazbalceta, como su biógrafo, que lo hacía descender precisamente de don Francisco el del Mixton. El nombre que usó el obispo, en caso de ser nieto del conquistador de México y no su hijo, no resolvería nada,

1. Arquidiócesis de Puebla, Excmo. Sr. don Alfonso de la Mota y Escobar (1608-1625), disponible en http://www.arquidiocesisdepuebla.mx/index.php/arquidiocesis/obispos-y-arzobispos/obispos/23excmo-sr-don-alfonso-de-la-mota-y-escobar consultado el 17 de mayo de 2018.

2. Arquidiócesis de Puebla, Excmo. Sr. don Alfonso de la Mota y Escobar (1608-1625).

3. Ramírez Cabañas, «Don Alonso de la Mota y su descripción de la Nueva Galicia», en <http://www. revistadelauniversidad.unam.mx/ojs_rum/files/journals/1/articles/3687/public/3687-9085-1-PB.pdf> [consultado el 18 de mayo de 2018]. 
puesto que pudiera justificarse por la costumbre de aquellos tiempos, la cual autorizaba a un vástago para elegirlo entre los varios que llevaron sus antepasados 4.

La información acerca de su infancia y juventud en general es escasa, señalando apenas que parte de su crianza y educación se desarrolló en el convento de Santo Domingo de México, en donde nació posiblemente su inclinación eclesiástica. Algunos autores señalan que realizó sus estudios de las primeras letras en el Colegio Imperial de «Santa Cruz» de Tlatelulco ${ }^{5}$. También fue bachiller de la Real y Pontificia Universidad de México en donde se doctoró en Teología. Consagrado al sacerdocio, se le otorgó el beneficio de Chiapa de Mota6.

Ordenado ya de sacerdote, fue cura de la parroquia de Chiapa, en el Arzobispado de México, que por el singular celo y suma bondad con que la administró, es conocida hasta ahora con el nombre de Chiapa de Mota?

Posteriormente viajaría a la península Ibérica para adquirir otro doctorado en Cánones en la prestigiada Universidad de Salamanca. Cabe advertir que el viaje mencionado fue gracias a una herencia de aproximadamente diez mil pesos ${ }^{8}$. En el viejo continente, el rey Felipe II lo designó como uno de sus predicadores y fue confesor de una de las infantas 9 .

Años más tarde se trasladó a España en comisión de la ilustre Academia de la Pontificia Universidad de México, dando a conocer allí sus grandes talentos, así en la corte como en la celebérrima Universidad de Salamanca, donde se graduó como Doctor en Sagrados Cánones; esta fama de sus singulares prendas y vasta cultura y literatura llegó hasta la Corte de Roma, formándose de él tan alto concepto que el entonces Sumo Pontífice, Sixto V, según se afirma, pensaba colocarlo en el Sacro Colegio de Cardenales y hubiera vestido sin duda la púrpura cardenalicia a no haber fallecido el mencionado pontífice ${ }^{10}$.

Concluida su labor en Europa en 1596, el Rey Felipe II lo presentó a la Santa Sede para los obispados de Nicaragua y Panamá que el prelado se negó a aceptar; el 22 de octubre de 1597 fue presentado para el obispado de Guadalajara, que era en ese momento «sede vacante» por el fallecimiento de don Francisco Santos García de Ontiveros y Martínez. En esta ocasión, don Alonso aceptó el cargo y tomó posesión del mismo mediante apoderado el 7 de noviembre de 1598, manteniéndose al frente de dicho obispado durante más de siete años, siendo modelo de

4. Ramírez Cabañas, «Don Alonso de la Mota y su descripción de la Nueva Galicia», p. 278.

5. Ver Arquidiócesis de Puebla, Excmo. Sr. don Alfonso de la Mota y Escobar (1608-1625).

6. Bermúdez de Castro, Diego Antonio, Theatro Angelopolitano o Historia de la ciudad de Puebla, Editado por Dr. N. León, México, 1985, p. 293.

7. Arquidiócesis de Puebla, Excmo. Sr. don Alfonso de la Mota y Escobar (1608-1625).

8. Ver Ramírez Cabañas, «Don Alonso de la Mota y su descripción de la Nueva Galicia», p. 278.

9. Bermúdez de Castro, Theatro Angelopolitano o Historia de la ciudad de Puebla, Editado por Dr. N. León, México, 1985, p. 294.

10. Arquidiócesis de Puebla, Excmo. Sr. don Alfonso de la Mota y Escobar (1608-1625). 
ejemplar prudencia y celo pastoral ${ }^{11}$. El prelado recibió el honroso cargo de deán del obispado de Michoacán, de donde fue trasladado posteriormente a la arquidiócesis de México en donde sostuvo una fuerte amistad con Gregorio López, hombre afamado por su virtud cristiana.

De su personalidad e inteligencia, se han ubicado opiniones uniformes y sumamente halagadoras de sus contemporáneos:

Que debió de gozar renombre por su inteligencia y sus luces lo atestiguan numerosos juicios de contemporáneos y de pósteros, como en los que siguen: «Es discreto y consumadísimo teólogo y de suave conversación, de gran vida y ejemplo y, sobre todo, bienquisto y más de los indios porque los confiesa y predica en su lengua, que sabe muy bien, con que les [es] más grato»; y el maestro González Dávila: «Y fue tan grande la opinión que tuvo, que en toda la Nueva España se tenía por asentado que si la santidad del Sumo Pontífice honrara a las Indias con los honores de capelo de cardenal, esta gracia había de ser para el obispo de la Puebla de los Ángeles; que la honra de las dignidades no está en tenerlas, sino en merecerlas». Fray Alonso Franco escribió a su turno: «Era amigo de la paz y buen gobierno de sus feligreses, que vivían edificados del ejemplo que les daba con su vida y con la doctrina de sus sermones, en que no era inferior a ninguno, y superior a muchos de los más aventajados predicadores de su tiempo» ${ }^{12}$.

\section{PRIMER OBISPO DE LA ANTIGUA DIÓCESIS DE TLAXCALA}

En 1590 se trasladó a la Puebla de los Ángeles, concordando con el inicio de la primera administración virreinal de Luis de Velasco el Joven.

Al fallecer Santos García, obispo de Guadalajara, en 1597, don Alonso de la Mota y Escobar fue designado como su sustituto, trabajando arduamente durante nueve años hasta que, finalmente el 26 de marzo de 1606, retornaría a la ciudad de Puebla en calidad de auxiliar del infatigable y experimentado obispo Diego Romano, siendo el primer criollo en desempeñar tal oficio. Su desempeño en dicho cargo fue de gran relevancia, ya que se desarrolló en concordancia con el momento de vejez y problemas visuales de monseñor Romano ${ }^{13}$.

El 26 de mayo de 1605 fue promovido como obispo auxiliar (el primer obispo auxiliar que registra el Episcopologio Angelopolitano) del Excelentísimo Sr. Romano y Gobea, obispo de Puebla, que era muy anciano, lleno de achaques y que se encontraba casi ciego, desempeñando dicho cargo, con abnegado celo apostólico, hasta el 12 de febrero de 1607, en que fue presentado para sucederle en la Sede Episcopal Angelopolitana, tomando posesión de ella, por poder otorgado al entonces Canónigo Maestrescuelas Lic. Pedro de la Vega y Sarmiento, el 19 de abril de $1608^{14 .}$

11. Ver Arquidiócesis de Puebla, Excmo. Sr. don Alfonso de la Mota y Escobar (1608-1625).

12. Ramírez Cabañas, «Don Alonso de la Mota y su descripción de la Nueva Galicia», p. 280.

13. Ver Salazar Andreu, 2005, p. 121.

14. Arquidiócesis de Puebla, Excmo. Sr. don Alfonso de la Mota y Escobar (1608-1625). 
Posteriormente, y con el fallecimiento de su antecesor en 1607, don Alonso se convertiría de forma definitiva en el prelado titular de la mitra angelopolitana. La noticia de su designación como titular de la mitra llenó de júbilo a la ciudad, emitiéndose el 25 de enero de 1608, un acuerdo del cabildo angelopolitano para recibir al nuevo obispo y llevarlo a la Iglesia catedral ${ }^{15}$. Lamentablemente los datos sobre el lugar, fecha y año de la Consagración Episcopal de don Alonso de la Mota, no han podido ser localizados.

Inmediatamente don Alonso comenzó la ardua tarea de recorrer su extensa diócesis, que colindaba con el Océano Atlántico y el Pacífico, haciéndose merecedor del apelativo de «Obispo Viajero». La constancia en sus largos recorridos y su presencia física y espiritual a lo largo del obispado reafirmaron la fuerza episcopal de cara a las órdenes religiosas, escuchando las necesidades de diversos sectores de su grey, pero en especial de los indígenas ${ }^{16}$.

Las limosnas de este caritativo prelado fueron continuas y crecidas, especialmente cuando salía a visitar la diócesis; su gobierno fue pacífico y benigno, con lo que se hizo amar y venerar de su clero y de sus diocesanos, que consideraban y veían en su santo prelado «a un padre amoroso siempre dispuesto a consolarlos en sus aflicciones y socorrerlos pródigamente en sus necesidades» 17.

\section{RELACIONES POLÍTICAS}

Mantuvo excelentes relaciones con las autoridades de la ciudad de Puebla, al grado que en 1615 el cabildo angelopolitano le otorgó, en beneficio de su huerto, una merced de ojo de agua en el barrio de San Sebastián, con la condición de solo usarla en día domingo. Dos años después las mismas autoridades solicitarían al prelado un préstamo de veinte mil pesos de oro, para resolver un adeudo previo que tenía la ciudad para con los herederos de Juan Rodríguez de Figueroa, y el cual se liquidó casi un año después ${ }^{18}$. No obstante, en 1625, el cabildo acordó un libramiento de mil pesos al rector del Colegio de San Ildefonso de la Compañía de Jesús «por el rédito de los 20.000 pesos que Alonso de la Mota y Escobar, obispo de Tlaxcala, donó al Colegio y que están empleados en los propios de la ciudad» ${ }^{19}$. Como puede apreciarse del acuerdo en cita, el dinero en mención estaba destinado a una de las principales obras del obispo Mota: la fundación del Colegio de San Ildefonso:

En enero de 1625 (dos meses escasos antes de su muerte), fundó el «Colegio de San Ildefonso» de estudios superiores, a cargo de los religiosos de la «Compañía de Jesús», que bien puede considerarse como el primer colegio de los jesuitas fundado en la ciudad de Puebla; al ser expulsados los religiosos de la «Compañía

15. Ver Acuerdo de cabildo, 25 de enero de 1608, vol. 14, documento 106, foja 63v, AMP.

16. Ver González Jácome, 1987, pp. 29-158.

17. Arquidiócesis de Puebla, Excmo. Sr. don Alfonso de la Mota y Escobar (1608-1625).

18. Ver Merced de ojo de agua al obispo Mota, 9 de enero de 1615, vol. 15, doc. 85, foja 52f, AMP y Acuerdo de cabildo, 19 de enero de 1618, volumen 15, doc. 252, foja 176f. AMP.

19. Acuerdo de cabildo de 21 de abril de 1617, vol. 15, doc. 209, foja 143v, AMP. 
de Jesús» de España y de todas sus colonias de ultramar, en 1767, por orden del rey Carlos III de España, este Colegio lo transformó el entonces obispo de Puebla, el Excelentísimo Sr. López Gonzalo, en «Hospicio de Pobres»; actualmente dicho colegio, que después fue hospital y hospicio de los niños, y que en el transcurso de los años ha sufrido muchas reformas y adaptaciones, sirve para albergar una pequeña escuela primaria, una escuela de arte y oficios para mujeres y unas oficinas de Beneficencia Pública del Estado20.

Los antecedentes de la obra señalada son interesantes: en 1622, y con el apoyo de los jesuitas, don Alonso pensó en establecer un hospital para indios bajo la advocación de San Ildefonso, pero poco antes de su muerte cambió de opinión, y destinó la ayuda para fundar un colegio de filosofía y teología para Jesuitas, asignando para ello, una hacienda de trigo con riego en el valle de Atlixco, denominada «Santa María», conocida posteriormente por «La Alfonsina»; así como una gran cantidad plata, alhajas y muebles, sin obviar el préstamo de oro señalado ya en líneas precedentes, que ascendieron a más de doscientos mil pesos ${ }^{21}$.

Don Alonso de la Mota y Escobar inició los trabajos de construcción del Palacio Episcopal22 que fueron completados por sus sucesores don Juan de Palafox y Mendoza y don Manuel Fernández de Santa Cruz. También el prelado contribuyó a la fundación del Convento de Religiosas de la Santísima Trinidad, y fue muy generoso con los indígenas cuando realizaba visitas pastorales a su Diócesis ${ }^{23}$.

La Arquidiócesis de Puebla señala:

Varón de gran espíritu progresista y de singular iniciativa, contribuyó a la fundación del convento de las religiosas de la Santísima Trinidad, cediéndoles, para su ampliación, su palacio episcopal, que había edificado a sus expensas, emprendiendo, después, la construcción del nuevo palacio episcopal, donde actualmente se encuentran las Oficinas de Correos y Telégrafos de Coliseo; las aderezó y dispuso de suerte que pidió habitar en ellas y después uno de sus sucesores: el Excelentísimo y Venerable Beato Juan de Palafox y Mendoza, que durante su gobierno aumentó mucho su construcción y, finalmente, el Excelentísimo Sr. Fernández de Santa Cruz terminó este magnífico palacio episcopal, actualmente en poder del Gobierno como propiedad federal 24

Con fecha de diciembre de 1619, se ha rescatado un llamativo documento en el cual consta que el cabildo poblano juró defender y predicar la Inmaculada Concepción de María, siendo visible la firma de don Alonso, así como de los capitulares. La muerte del rey Felipe III fue otro de los importantes acontecimientos que don Alonso de la Mota tuvo que atender en su calidad de obispo, preparando las honras

20. Arquidiócesis de Puebla, Excmo. Sr. don Alfonso de la Mota y Escobar (1608-1625)

21. Ver Fernández Echeverría y Veytia Mariano, 1931, pp. 423-424.

22. Actualmente localizado en la calle 5 oriente y la esquina de 16 de septiembre en la Ciudad de Puebla de Zaragoza.

23. Ver Fernández Echeverría y Veytia, 1931, pp. 193-194

24. Arquidiócesis de Puebla, Excmo. Sr. don Alfonso de la Mota y Escobar (1608-1625). 
fúnebres y exequias correspondientes, tras la solicitud que de ello hiciera el cabildo poblano mediante Acuerdo de 5 de agosto de $1621^{25}$.

\section{RELACIONES CON EL CLERO SECULAR Y REGULAR}

Pero si las relaciones políticas de monseñor De la Mota fueron fructíferas, sus relaciones con órdenes regulares, si bien cordiales, no fueron idóneas, presentándose algunos enfrentamientos desde 1617, que alcanzaron fechas posteriores a la muerte del prelado.

El cabildo municipal, en su resolución de 21 de abril de 1617 ordenó:

Acuerdo para que el regidor Juan de Narváez, procurador mayor, presente ante el obispo de Tlaxcala, Alonso de la Mota y Escobar, la bula dada por el papa Paulo $\checkmark$ en la que especifica que a las personas que pidan ser enterradas en los monasterios, no se les cobre más de lo que se cobra a los que se entierran en la catedral, y les pida haga se cumpla, para ellos se le da poder.

Este acuerdo es en virtud de la solicitud hecha por fray Pedro Gallo, procurador del convento de San Agustín, de la cual se hace traslado.

Ante esta petición del cabildo al obispo, al parecer la injerencia agustina sirvió de instrumento para exigir a las otras congregaciones religiosas del obispado el irrestricto cumplimiento de la orden papal, o quizá don Alonso fue tibio en el acatamiento de dicho mandato, a fin de evitar fricciones con el poderoso clero regular de la diócesis angelopolitana ${ }^{26}$.

Pero de las órdenes religiosas imperantes en la ciudad de Puebla, sería con los miembros de la Compañía de Jesús con quien mantendría una fructífera y amable relación, con quienes, como ya se mencionó, trabajó en pro de la educación y de los indígenas; sin embargo, a la muerte de don Alonso, el cabildo poblano se tuvo que enfrentar con los jesuítas por el incumpliemnto de la voluntad del obispo en relación con unos cursos de arte, que se refleja en un Acuerdo de fecha 13 de agosto de 1627, con el que se facultaba a dos regidores para solicitar ante el provincial de la Compañía de Jesús que no se modificaran los cursos de arte que había fundado el prelado en estudio ${ }^{27}$.

Para que Alonso Corona, escribano público, mediante la autorización de la Compañía de Jesús, saque un traslado de la donación, institución, patronazgo y fundación del Colegio de San Ildefonso, la cual fue hecha por Alonso de la Mota y Escobar, obispo de Tlaxcala. A su vez se busquen todos los papeles relacionados a la fundación para que se entreguen a Juan de Narváez, regidor, y a Juan de Carmona Tamariz, depositario general y procurador mayor, para que juntos con un letrado exijan ante los que imparten cátedras de arte se acaten a las condiciones establecidas por dicho obispo 28 .

25. Acuerdo de cabildo de 5 de agosto de 1621, vol 16, doc. 51, foja 53f, AMP.

26. Salazar Andreu, 2005, pp. 124-125.

27. Ver Acuerdo de cabildo de 13 de agosto de 1627, vol. 17, doc. 71, fojas 67v-68f, AMP.

28. Acuerdo de cabildo de 13 de agosto de 1627, vol. 17, doc. 71, fojas 67v-68f, AMP. 
También las relaciones del prelado con el arzobispo de México, Juan Pérez de la Serna y la Audiencia de México tuvieron complicaciones, destacando el enfrentamiento que sostuvieron el virrey marqués de Gelves y monseñor Pérez de la Serna, originado por el férreo e inflexible carácter de ambos personajes, así como el conflicto que se tuvo con Melchor Pérez de Veraiz, alcalde mayor de Metepec, contra quien el virrey actuó judicialmente, encontrándose con la oposición del arzobispo quien acogió al Alcalde mayor, bajo la figura de la inmunidad eclesiástica. Lo anterior derivó en una serie de amenazas y retos en los que el poder temporal y eclesiástico midieron fuerzas. Finalmente el conflicto tuvo que ser resuelto por un delegado apostólico enviado por el papa Gregorio XIII, que era un clérigo de la Puebla de los Ángeles ${ }^{29}$.

El 14 de enero de 1624, se presentó un amotinamiento por gran parte de la población, ya que estando el arzobispo Pérez de la Serna en Teotihuacán, se le informó que el virrey había ordenado que lo llevasen al Puerto de Veracruz, orden a la que prestó resistencia, provocando que la gente rompiera las puertas del Convento de Santo Domingo para sacar a don Melchor Pérez, para luego dirigirse al Palacio Virreinal, con el propósito de incendiarlo, situación en la cual el Marqués de Gelves evitó el enfrentamiento y salió disfrazado, refugiándose en el Convento de los Padres Franciscanos. Posteriormente el arzobispo Pérez de la Serna, se presentó en la Ciudad de México, siendo recibido con gran júbilo por sus habitantes y con el sonido de las campanas de la capital, procediendo a abrir los templos que permanecieron cerrados por causa de las disputas, y absolvió a los excomulgados con excepción del virrey ${ }^{30}$.

Poco tiempo después a estos acontecimientos, en 1625, don Alonso de la Mota y Escobar fallecería con un obispado que aún aguardaba la llegada de recursos para continuar los trabajos de construcción de la catedral:

Después de gobernar a su extensa diócesis, con ejemplar prudencia y edificante bondad, por espacio de diecisiete años, menos diecisiete días, falleció, el 16 de marzo de 1625, en su palacio episcopal de la ciudad de Puebla.

Después de las solemnes «honras fúnebres» celebradas en S. Catedral, su cadáver, acatando su última voluntad, fue sepultado en el templo de San Ildefonso de la ciudad de Puebla, donde actualmente reposan sus restos mortales ${ }^{31 .}$

\section{BiBLIOGRAFÍA}

Arquidiócesis de Puebla, Excmo. Sr. don Alfonso de la Mota y Escobar (1608-1625), disponible en <http://www.arquidiocesisdepuebla.mx/index.php/arquidiocesis/obispos-y-arzobispos/obispos/23-excmo-sr-don-alfonso-de-la-motay-escobar>.

31. Arquidiócesis de Puebla, Excmo. Sr. don Alfonso de la Mota y Escobar (1608-1625). 
Bermúdez de Castro, Diego Antonio, Theatro Angelopolitano o Historia de la ciudad de Puebla, ed. Nicolás León, México, Universidad Nacional Autónoma de México,1985.

Fernández Echeverría y Veytia, Mariano, Historia de la fundación de la ciudad de la Puebla de los Ángeles en la Nueva España. Su descripción y presente estado, México, Imprenta Labor, 1931.

González Jácome, Alba, Fray Alonso de la Mota y Escobar. Memoriales del obispo de Tlaxcala. Un recorrido por el centro de México a principios del siglo XVII, México, Secretaría de Educación Pública del Estado de Tlaxcala, 1987.

Hanke, Lewis, Los virreyes españoles en América durante el gobierno de la Casa de Austria, Madrid, Atlas, 1977.

Ramírez Cabañas, Joaquín, «Don Alonso de la Mota y su descripción de la Nueva Galicia», Revista de la Universidad Nacional Autónoma de México, febrero de 1931, disponible en <http://www.revistadelauniversidad.unam.mx/ojs_rum/ files/journals/1/articles/3687/public/3687-9085-1-PB.pdf>.

Salazar Andreu, Juan Pablo, Obispos de Puebla en el periodo de los Austria (15211700), México, Porrúa, 2005.

Torner Florentino, Resumen Integral de México a través de los siglos, México, 1967.

\section{FUENTES MANUSCRITAS}

Archivo Municipal de Puebla (AMP).

Volumen 14, documentos: 35 y 106.

Volumen 15, documentos: 85 a 252.

Volumen 16, documentos: 51 a 305.

Volumen 17, documentos: 71 y 72. 